\title{
The attitudes of elementary and middle school students and teachers towards online learning during the corona pandemic outbreak
}

\author{
Asmahan Masry-Herzallah $^{1}$ D $\cdot$ Yuliya Stavissky $^{2}$
}

Received: 18 August 2020 / Accepted: 12 February 2021 / Published online: 9 March 2021

(c) The Author(s), under exclusive licence to Springer Nature Switzerland AG part of Springer Nature 2021

\begin{abstract}
The coronavirus pandemic has impacted the education systems worldwide and most, including the Israeli, have transitioned to online learning. Moreover, closing schools has extreme social, cultural, educational and economic implications on the student, teacher and parent populations. This is especially true for students from families of lower-socio-economic status and young students who need parental assistance. Furthermore, online learning is not suitable for all teachers, because some lack the technological capabilities needed. To examine the attitudes of teachers and students towards online learning, questionnaires were administered to 476 students, grades 3-7 and 250 teachers from the Arab and Jewish sectors. The findings revealed that age plays an important role both among teachers and students, where mainly younger children and older teachers encounter difficulties in this transformation. Furthermore, gender and sectoral differences were found both among teachers and students. These findings show that conversion to online learning may widen the existing gaps.
\end{abstract}

Keywords Online learning · Gender and sectoral gaps · Technological capabilities · Attitudes

Asmahan Masry-Herzallah

asmahan.masry@mail.huji.ac.il

Yuliya Stavissky

123yul45@walla.co.il

1 Al Qasemi Academic-College of Education, The Hebrew University of Jerusalem, Jerusalem, Israel

2 The Hebrew University of Jerusalem, Jerusalem, Israel 


\section{Introduction}

The education systems throughout the world, like other social systems, have been impacted as a result of the Corona pandemic and school closures have occurred worldwide (Reich et al. 2020). Due to the characteristics that designate the cessation of current activities in all of the formal and informal education frameworks, the closing of schools has extensive social, cultural, educational and economic impacts that effect students, teachers and parents (Reich et al. 2020; Reykdal 2020; Schleicher 2020). These characteristics signify the risks that might emerge in the education system during the Corona crisis.

Online learning is the only evident response in this time of emergency. With the help of online learning knowledge can be bestowed to the learners (Reich et al. 2020), while providing emotional solutions to students and a supportive social-educational framework (Schleicher 2020). Despite its advantages, apparently online learning does not suit all students and teachers. Presumably, the cessation of all activities in the schools, including extra-curricular activities, will have an effect, first and foremost, on students from the weaker social strata (Reich et al. 2020; UNESCO 2020), mainly because of their lack of digital means. This is combined with the fact that school for these students is one of the three main frameworks in which they spend most of their day, with the second being informal extra-curricular frameworks such as after-school centres and lastly their home. (Dahan et al. 2020).

Furthermore, studies show that online learning apparently is unsuitable for young students who require parental assistance with this type of learning (Reich et al. 2020; Welner 2020). Moreover it creates substantial problems and difficulties related to widening the disparities between the students (Dynarski 2018; Welner 2020), to the digital divide and to the gaps in the support and abilities of the parents to assist their children (Bazzaz 2020; Weisblai 2020). This is especially apparent in the expected implications of online teaching among teachers who teach students from the weaker socio-economic strata.

Studies also indicate gender differences in technological command and digital literacy among male and female teachers in favour of male teachers (DeYoung and Spence 2004; Hung and Hsu 2007; Amzalag and Masry-Herzallah, 2021; van Braak et al. 2004). Moreover, current studies argue that the cultural context also cannot be ignored in online learning (Aparicio et al. 2016; Sobodić et al. 2017). These studies claim that cultural aspects of teaching and learning styles must be taken into account in the technological space, and variables such as nationality, gender, tradition and values should be addressed, as they are connected to learning approaches and teaching processes in the online space and in general (Moore et al. 2005; Jung and Gunawardena 2015).

Similar to all of the education systems throughout the world, the education system in Israel also underwent a transition to online learning. The Ministry of Education's response to the current crisis was characterized by ambiguity, confusion, and changing as well as contradicting guidelines (Dahan et al. 2020).

It is important to note that there is evident inequality in Israel between the Jewish and Arab communities. For example, hundreds of thousands of Arab families do not 
have access to the technological means necessary for online learning (Dahan et al. 2020).

It is known that a digital divide exists between the Arab and the Jewish societies (Ganayem 2018), in addition to the cultural differences that may affect the teaching and learning processes in the online learning realm (Masry-Herzallah and Amzalag 2019).

Thus, the aim of this study is to comparatively examine the attitudes, sense of technological ability and sense of success of online learning (synchronous and asynchronous) among Jewish and Arab teachers, and male and female students in elementary and middle schools in Israel during physical school closures in Israel due to the outbreak of the coronavirus (Covid-19) pandemic.

The main argument which is the basis of this study is that women/female students, Arabs, young students and older teachers have lower technological abilities and thus find online learning to be more difficult. The goal of this research is to draw attention to the underprivileged communities (women, Arab, older) and young students and their difficulty in using the technologies - from both sides, i.e. the teacher and the students, in the immediate and sudden transition to online learning.

The current study aimed to examine the following research questions:

1. What are the attitudes, feelings, technological abilities and sense of success of students and teachers towards combined online learning and teaching (synchronous and asynchronous) as a result of the Covid-19 pandemic?

2. Will differences be found regarding these attitudes and feelings between Jewish teachers and Arab teachers in a comparison based on gender, age and the grade levels taught?

3. Will differences be revealed concerning these attitudes and feelings between Jewish students and Arab students in a comparison based on gender, age and grade level?

\section{Literature review}

\section{Online teaching and learning}

The technological revolution also resulted in reform in the field of teaching and learning (Avidov-Ungar and Eshet-Alkalai 2014; Kale and Goh 2014). In recent years, we have been witnessing the growing integration of technologies in the education system with the development of the 21st century skills (Bishop 2006). This integration also has led to the development of online learning in higher education (Kale and Goh 2014). Online learning is influenced for the most part by the constructivist approach to teaching and learning (Reid-Martinez and Grooms 2018). Researchers emphasize the use of the constructivist theories as the rationale and a fundamental principle for teaching-learning that is adapted to network technologies (Chou 2004). The combination of the constructivist approach and the principles of online learning and its application in teaching processes makes it possible to create 
an environment in which the education approach which places the student at the center can be expressed, strengthens his involvement in the studies and encourages development as an independent learner with self-direction, abilities and capabilities to build his knowledge and form connections between the contents with the goal of building new knowledge (Amzalag and Masry-Herzallah 2021; Ford and Russo 2006).

The "classic" format of online learning was founded on asynchronous teaching, where the technology connects the students and the teacher with no dependency on time and place. This includes independent reading and individuality of study material, performing different tasks with the aim of strengthening the command and comprehension of the material, and examining these skills by means of the system (Reid-Martinez and Grooms 2018). After years of online learning in this manner, in recent years different models have been developed such as synchronized learning, where the technology connects the students and the teacher, requires attendance at the same time, but not necessarily in the same place (Chauhan 2017).

These types of learning have been applied by schools during the Coronavirus pandemic. Nonetheless research concerning online learning in the context of the education system has not been sufficiently examined, in contrast to research in this field of learning in higher education (Reid-Martinez and Grooms 2018).

Studies reveal that asynchronous learning is advantageous because it facilitates the students' ability to cope with limitations of time and place. In contrast to regular programs, online learning enables more flexibility, and increases access (Bryant and Bates 2015). However, some of the students do not succeed in forming effective interaction with the teachers and their peers through the Internet, creating problems for them and for the teachers. Different studies indicate the importance of the interaction that occurs in the online environment, the lack of which creates a sense of isolation thereby increasing the risk for dropout or scholastic failure (Shelton et al. 2017). Online learning (synchronous and asynchronous) is usually structured around written communication which can be more calculated and profounder than verbal learning (Fedynich et al. 2015). Exposure to pedagogic applications and online teaching strategies including experience with them during the learning process by means of investigative, dialogic and experiential learning assists the learners to function better in the technological environment during the process and will help improve their functioning later in life (Campbell 2018; Dabbagh 2007).

\section{Online learning at schools}

In recent years, an increasing number of researchers have begun to study online learning in schools. These studies indicate that online learning does not suit every student in the education system and may affect the principle of equal education among students (Schleicher 2020). This is due to the fact that not all students in the education system enjoy the same environmental conditions at home that allow them to study online (Welner 2020). In addition, the presence and support of parents who can assist their children with these studies is not available to all students, because not all parents are accessible for this purpose or technologically capable. Further 
to the digital divide, online learning relies on the extensive involvement of parents of young children and in older ages on their ability to independently study. Parental involvement and independent study are obviously affected by the socio-economic background of the students' families and their families' cultural capital. Thus, even if we exclude the digital divide, the online learning model might broaden the existing educational gaps, in any case (Schleicher 2020).

The initial evidence of the growing gap in the transition to online learning can be found in current research on the subject of complete online learning schools. These studies found that in general students who study in this type of school achieve lower grades and fail more frequently in comparison to students at regular schools. Seemingly, the students affected most are those with low achievements (Ahn and McEachin 2017; Fitzpatrick et al. 2020).

\section{Students, teachers and online learning and teaching—promoting and inhibiting factors}

Teachers might also encounter difficulties and frustration in the transition to online teaching, especially in light of the characteristics of the $\mathrm{Z}$ and Alpha generation students. The students of these generations are characterized by their wide use of digital search banks and digital interpersonal communication. To a certain degree we can even say that their socialization process is done via the internet. Their response rate is rapid and they search for quicker solutions than others (Seemiller and Grace 2017). Consequently, this reality warrants drastic changes in the definition of the role of the teacher who will be asked to teach online, as not all of the teachers are qualified for the pedagogic and technological changes that are necessary in online learning models (Anderson et al. 2019). Actually, while the students are Z and Alpha generation students, frequently the teachers belong to the X-generation. At times this generation is denoted "digital immigrants" (Prensky 2001), because they are immigrants to the digital world of the next one or two generations. This migration might be accompanied by great frustration, especially when the teacher is required to incorporate distance teaching, namely teaching that demands different skills than those needed in the traditional teaching process (Luthra and Mackenzie 2020). This is especially true during times of crisis such as the outbreak of the corona pandemic, when the teacher also takes on the important role of strengthening the students' psychological wellbeing (Elias et al. 2019).

Studies indicate gender differences in the command of the technology and digital orientation in favour of men (Rafaeli et al. 2018), also in reference to the education system (DeYoung and Spence 2004; Masry-Herzallah and Amzalag 2019; van Braak et al. 2004). The digital divide and the different nature of online learning have suddenly become critical. During the coronavirus pandemic, the transition from traditional learning to full online learning for all students in the education system has been immediate and intense. Added to the many roles of the teacher are additional tasks such as involving parents in the teaching, especially those of young students in elementary school. This is necessary because the younger children are incapable of 
succeeding in online learning without the full supervision and assistance of parents (Welner 2020).

\section{Online learning in the Israeli education system during the corona pandemic}

One of the main characteristics of the Israeli education system, which does not operate in isolation from the social, economic, cultural and political reality in which it exists, is the inequality between the different groups of students. This inequality includes strata, ethnic and national aspects. The national and international achievement tests indicate divides between different groups in Israel. These gaps are of the highest among the OECD countries (Blass 2019). These gaps are expressed in entitlement to matriculation certificates in different regions in Israel, with a clear connection between socio-economic strata and the rate of success on matriculation exams (Weiss 2018). Furthermore, the data regarding Meitzav (school growth and efficiency measures) exams indicate gender-related gaps between boys and girls in favour of girls in all levels of education and in all subjects including mathematics and technology (Ayalon et al. 2019). In more than 24\% of the homes in Israel there is no Internet and in $15.7 \%$ there is no computer. The percentage of Arab citizens who are not connected to the internet is higher and the use of computers among the Jewish population is twice as high as the use among the Arab population (Central Bureau of Statistics 2020).

\section{Online learning in the Arab education system during the corona pandemic}

In the Israeli context, characterized by inequality, especially between education in the Jewish sector and the Arab sector, these gaps are also expressed in the entitlement to a matriculation certificate (Ayalon et al. 2019). In the context of integrating computerization and information technology in the education system in the Arab sector, studies show extensive gaps in reference to computerization and information technology between schools in the Jewish sector and those in the Arab sector (Husny-Arar and Massry-Herzallah 2016). This divide has intensified the digital gaps that exist in any case between the Jewish and Arab societies and affects the extent of the use of digital means in education on a daily basis, with implications on the degree of preparedness for use of these means during times of crisis.

This situation has had a significant effect on the preparedness of the Arab sector in the education system in emergency times during the breakout of the coronavirus, which limits the number of students (and part of the teachers) who participate in online learning. About half of the Arab students are not continuously connected to online learning; in some areas online learning does not transpire due to lack of infrastructure, shortage in suitable end devices and lack of the ability of parents to help their children and digital divide in the Arab society. Also, the level of preparedness of the schools and the investment in training the staff in the Arab society is lower than the Jewish society. Moreover, the central platform for online learning is based 
on the Hebrew language only in addition to the scarcity of digital contents, video clips as well as presentations in Arabic (Dahan et al. 2020).

Seemingly, during the coronavirus crisis and the transition to online learning there has been little reference to the fact that not all the students in the education system enjoy the same environmental conditions at home that allow them to learn online. The presence and support of parents who can assist in learning is absent at times. The support of parents is critical for young students because online learning relies on greater parental involvement for young ages and the ability to learn independently in the older ages.

Based on the above review of literature, we selected the significant variables that affect the promotion of online teaching of the teachers both from the perspective of the personal traits of the teachers (sector, gender, age, technological abilities), the level of education that they teach (elementary and secondary) and the socioeconomic status of the students. For the students we chose to examine personal variables (age, gender and grade level), in addition to the variable of asking for help. We decided to examine this variable in light of the fact that elementary school children need the help of their parents due to lack of technological capabilities at their age or the level of comprehension required of them to understand the online learning instructions.

In this study, we presumed a connection would be found among the teachers between the sector, gender and type of school and the dependent variables: attitudes towards online learning, the extent of the use of online learning and technological ability. Consequently, our hypothesis was that findings will show that male teachers, Jewish teachers and teachers in the higher grades have more positive attitudes towards online teaching and they make more use of it and they have more technological abilities.

With reference to the students, we presumed that a connection will be found between the sector, gender and age group and the dependent variables: success in online learning, technological abilities, attitudes towards online learning and requesting assistance. Thus, the male, Jewish and higher-grade students will be more successful in their online studies, will have better technological abilities, more positive attitudes towards online learning and will be more apt to requesting assistance than others when they need it.

\section{Method}

\section{Participants}

The teachers in this study totalled 250 ( $85.2 \%$ females), who participated by means of an online questionnaire sent to them on the Google Docs platform. Of these teachers 114 (45.6\%) teach in the Jewish sector, 128 (51.2\%) in the Arab sector and eight (3.2\%) in other frameworks. Furthermore, 108 (43.2\%) teach in elementary schools and $142(56.8 \%)$ in middle schools. The average age of the teachers in this sample was $40.5(\mathrm{SD}=9.25)$, and they teach a wide variety of subjects online (see Table 1$)$. 
Table 1 Distribution of teachers by primary taught subject

\begin{tabular}{lcc}
\hline Grade & $\#$ & $\%$ \\
\hline Hebrew & 123 & 26 \\
Mathematics & 114 & 24 \\
English & 67 & 14 \\
Arabic & 62 & 13 \\
Science & 57 & 12 \\
Humanities & 52 & 11 \\
\hline
\end{tabular}

Table 2 Distribution of students by grades

\begin{tabular}{lcl}
\hline Grade & $\#$ & $\%$ \\
\hline Third & 52 & 10.9 \\
Fourth & 20 & 4.2 \\
Fifth & 68 & 14.3 \\
Sixth & 72 & 15.1 \\
Seventh & 81 & 17.0 \\
Eighth & 99 & 20.8 \\
Ninth & 84 & 17.6 \\
Total & 476 & 100 \\
\hline
\end{tabular}

In addition, students also answered an online questionnaire by means of a link sent to them or their parents on the Google Docs platform. Responses were received from 476 students (55\% female). Of the students, 193 (40.5\%) are from the Jewish sector and $283(59.5 \%)$ are from the Arab sector. The average age of the students was 12.26 ( $\mathrm{SD}=1.95)$. The students and the teachers belong to the same schools. Table 2 demonstrates the distribution of the students according to grades.

\section{Procedure}

After obtaining the needed approval from the ethics committee at the Academic college of Author 1, the questionnaires were distributed using the Internet (Google forum) along with forms explaining the study's purpose and making sure that the respondents (teachers and students' parents) are aware that questionnaires will remain anonymous. Students' questionnaire: The link to the online questionnaire was first sent to the students' parents for approval by means of a WhatsApp group of the students' parents. It was initially sent to the researchers' acquaintances, and then further distributed to additional parents via snowball sampling (Biernacki and Waldorf 1981). After their approval, the parents were asked to present the questionnaire to their children. Teachers' questionnaire: initially the teachers' questionnaire was sent to the researchers' acquaintances, including friends and teaching staff at different schools in different parts of Israel. Similarly, this questionnaire was also 
distributed to additional teachers via snowball sampling (Biernacki and Waldorf 1981). The responses to the teachers' questionnaire were received between April 3, 2020 and April 12, 2020. Responses to the students' questionnaire were received between April 3, 2020 and April 13, 2020.

\section{Measures}

In order to examine the study variables among the students and the teachers, questionnaires were drafted especially for this study. To enjoy the most cooperation to participate as possible the questionnaires were constructed so that they would be as brief as conceivable while taking into consideration the task load that characterizes the period of the coronavirus pandemic. The questionnaire for the teachers included 18 statements designated to examine three main variables: (1) extent of the use of online teaching. This variable included three statements, e.g. "at what frequency did you initiate online lessons and were in contact with the students?"; (2) technological abilities. This variable included four statements, e.g. "to what degree would you define yourself as a digital/technological person?"; (3) positive attitudes towards online teaching. This variable also included four statements, e.g. "to what extent does online teaching facilitate contact with your students". In addition, the questionnaire included demographic questions such as age, gender, sector, grades and subjects taught. The questionnaire for the Arab teachers was translated to Arabic. To check whether the questionnaire meets psychometric standards, a confirmatory factor analysis (CFA) and reliability tests were conducted (see results of CFA and reliability analysis below). As can be seen from the results, the questionnaire meets these standards.

The students' questionnaire was also constructed especially for this study and was also designated to be as brief as possible. The questionnaire included 19 statements intended to measure four variables: (1) success in studying online. This variable included four statements, for instance: "to what degree did you learn new things via online learning?"; (2) technological capability. This variable also included four statements. For example: "to what degree do have command of the use of the Internet?"; (3) attitudes towards online learning. This variable also included four statements, e.g. "to what degree does the online learning method allow you flexibility and suitability to your schedule?"; (4) asking for assistance. This variable included three statements designated to measure the degree to which the student asked for help from others in order to cope with online learning. For example, "to what extent did you use the help of peers with online learning?". The questionnaire included demographic questions such as age, gender, sector, grades and so forth. The questionnaire for the students studying in the Arab sector was translated to Arabic. The questionnaire underwent a confirmatory factor analysis (CFA) and reliability tests and was found to meet the accepted standards as shall be detailed later. The scales of the answers for the two questionnaires (the teachers' questionnaire and students' questionnaire) were measured on a 5-point Likert scale $(1=$ "not at all", $5=$ "very much"). 
Table 3 Goodness-of-Fit measurement found for the study questionnaires

\begin{tabular}{llllllll}
\hline Questionnaire & $\begin{array}{l}\text { Final no. of } \\
\text { items }\end{array}$ & $\begin{array}{l}\text { No. of measured } \\
\text { variables }\end{array}$ & $\chi^{2}$ & df & CFI & RMSEA & SRMR \\
\hline Teachers & 11 & 3 & 100.71 & 55 & 0.94 & 0.08 & 0.05 \\
Students & 15 & 4 & 364.63 & 84 & 0.91 & 0.08 & 0.05
\end{tabular}

CFI Comparative Fit Index, RMSEA root mean square error of approximation, SRMR standardized root mean square residual, $d f$ degrees of freedom, $\chi^{2}$ chi-square value

Table 4 Averages of the main study variables measured for the teachers, their internal reliability and the correlations between them

\begin{tabular}{lrllllllll}
\hline Variable & $M$ & SD & 1 & 2 & 3 & 4 & 5 & 6 & 7 \\
\hline 1. Age & 40.50 & 9.25 & - & - & - & - & - & - & - \\
2. Gender $^{\mathrm{a}}$ & 1.85 & 0.36 & -0.09 & - & - & - & - & - & - \\
3. Sector $^{\mathrm{b}}$ & 1.53 & 0.50 & -0.09 & -0.06 & - & - & - & - & - \\
4. School $^{\mathrm{c}}$ & 1.57 & 0.50 & 0.03 & -0.11 & -0.04 & - & - & - & - \\
5. Use & 3.39 & 0.79 & $-0.18^{* *}$ & -0.03 & -0.07 & 0.06 & $(0.62)$ & - & - \\
6. Ability & 3.57 & 0.80 & $-0.19^{* *}$ & $-0.14^{*}$ & 0.05 & 0.11 & $0.49^{* * *}$ & $(0.85)$ & - \\
7. Attitudes & 3.40 & 0.67 & -0.04 & -0.09 & -0.06 & 0.06 & $0.48^{* * *}$ & $0.66^{* * *}$ & $(0.63)$ \\
\hline
\end{tabular}

$N=250$; in parentheses $=$ Cronbach's alpha internal reliability score

$M$ mean, $S D$ standard deviation

${ }^{a}$ Dummy coding $(1=$ male, 2 = female $)$

${ }^{\mathrm{b}}$ Dummy coding $(1=$ Jew, 2 = Arab)

${ }^{\mathrm{c}}$ Dummy coding $(1=$ elementary school, 2 = middle school $)$

$* p<0.05 ; * * p<0.01 ; * * * p<0.001$

\section{Factor analysis}

We conducted two CFAs, one for the teachers' questionnaire and the other for the students' questionnaire. The analysis was conducted by means of the LAVAAN package (Rosseel 2012) with the R language (R-Core-Team 2018). As depicted in Table 3, the goodness-of-fit measurements are sufficient (Kenny 2020). The measurements presented in the Table (desired values appear in parentheses) are: Comparative Fit Index (CFI > 0.90), Root Mean Square Error of Approximation (RMSEA $<0.08$ ) and Standardized Room Mean Square Residual (SRMR < 0.08).

After confirming that the questionnaires that we constructed had sufficient goodness-of-fit values, we also checked the internal reliability of the variables measured in each questionnaire, which will be presented later. Below are the descriptive statistics and the results of the hypothesis testing for the teachers and for the students (Tables 4 and 5, respectively). 
Table 5 Averages of the main study variables measured for the students, their internal reliability and the correlations between them

\begin{tabular}{|c|c|c|c|c|c|c|c|c|c|}
\hline Variable & $M$ & SD & 1 & 2 & 3 & 4 & 5 & 6 & 7 \\
\hline 1. Grade $^{\mathrm{a}}$ & 6.56 & 1.89 & - & - & - & - & - & - & - \\
\hline 2. Gender ${ }^{b}$ & 1.55 & 0.50 & .01 & - & - & - & - & - & - \\
\hline 3. Sector ${ }^{\mathrm{c}}$ & 1.59 & 0.49 & $-0.34^{* * *}$ & 0.00 & - & - & - & - & - \\
\hline 4. Success & 3.15 & 0.91 & -0.03 & 0.04 & 0.04 & $(0.69)$ & - & - & - \\
\hline 5. Ability & 3.28 & 0.90 & $0.12^{*}$ & 0.02 & -0.08 & $0.77^{* * *}$ & $(0.78)$ & - & - \\
\hline 6. Attitudes & 3.00 & 0.92 & 0.09 & 0.05 & $-0.13 * *$ & $0.78 * * *$ & $0.73 * * *$ & $(0.75)$ & - \\
\hline 7. Request help & 2.46 & 0.90 & 0.09 & 0.06 & $-0.26 * * *$ & -0.01 & -0.07 & $0.12 *$ & $(0.54)$ \\
\hline
\end{tabular}

$N=476$; in parentheses = Cronbach's alpha internal reliability score

$M$ mean, $S D$ standard deviation

$* p<0.05 ; * * p<0.01 ; * * * p<0.001$

${ }^{\mathrm{a}}$ Dummy coding $\left(3=3^{\mathrm{r}} \mathrm{d}\right.$ grade, $4=4$ th grade and so forth)

${ }^{\mathrm{b}}$ Dummy coding $(1=$ male student, $2=$ female student $)$

${ }^{\mathrm{c}}$ Dummy coding $(1=$ Jewish, 2 = Arab $)$

\section{Findings}

\section{Teachers}

Table 3 shows the averages of the variables measured among the teachers, the Pearson correlations between them and Cronbach's alpha internal reliability score. Selected demographic parameters are also presented in Table 3.

As demonstrated in Table 3, there are relatively strong positive and statistically significant correlations between the three dependent variables: the frequency of the use of online teaching, technological ability and attitudes towards online learning. In accordance with the research hypothesis, a negative and statistically significant correlation was found between the age of the teacher and his/her degree of use and the teacher's technological ability. Thus, the older the teacher, the less they report on use of online teaching and less technological abilities.

The research hypotheses assumed that a correlation would be found between the sector, gender and type of school (elementary/middle), and the dependent variables: the frequency of the use of online teaching, technological abilities and attitudes towards online teaching. In order to examine the research hypotheses, a Three-Way MANOVA analysis was conducted. The model tested was in the form of 2 (male/female) $\times 2$ (Jewish/Arab sector $) \times 2$ (elementary/middle school). Eight teachers that reported teaching in other sectors rather than Jewish or Arabic were excluded from this analysis, as well as all analyses in which sector was a factor. We did not find any three-way interaction for the extent of use of online teaching, $F(1,231)=0.51, p=0.48$, or for the technological ability variable $F(1,231)=0.29, p=0.59$, or the attitudes variable $F(1,231)=1.85, p=0.18$. Two-way interactions were also not found. A main effect was found with reference to the gender variable for the dependent variable of technological ability, 


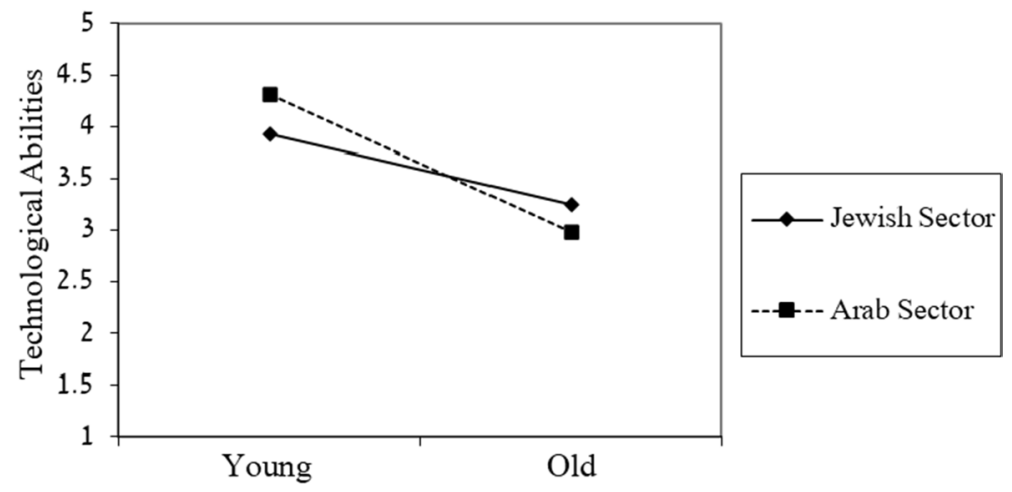

Fig. 1 Interaction between sector and age in predicting technological abilities

$F(1,231)=5.26, p=0.02$ where men $(M=3.98, \mathrm{SD}=0.86)$ were found to have higher technological abilities than the women $(M=3.53, \mathrm{SD}=0.76)$. Though a significant interaction effect was not revealed, another test that we conducted demonstrate that elementary school teachers who teach in the Jewish sector use online teaching more $(n=45, M=3.55, \mathrm{SD}=0.74)$ than those who teach in the Arab sector $(n=57, M=3.19, \mathrm{SD}=0.65)$ with statistical significance, $t(100)=$ 2.57, $p=0.01$. No other statistically significant effects were revealed.

Because almost no differences were found between the teachers from the Jewish sector and those from the Arab sector with reference to the study variables, and because this was the key research hypothesis, we decided to further examine whether there is a possible mediating variable in the connection between the sector and the three dependent variables. We decided to check whether age is a mediating variable in the relationship because apparently age is connected to part of the study's dependent variables and online learning technology is frequently perceived as more of a challenge for older people. In order to examine whether age possibly mediates connections between the sector and the study variables we used the PROCESS macro for SPSS (Hayes 2018). This common, well-known and accepted macro enables the examination of mediation and moderation in a convenient and economical manner. By means of this supplement, age was found to mediate the relationship between sector and technological ability, where the interaction variable between sector and age was found to be significant in predicting technological ability $b=-0.35, S E=0.01,95 \%$ CI $[-0.06$, - 0.01]. The interpretation of the model reveals that for Jewish teachers, there is no statistically significant relationship between age and technological ability $r$ $=-0.01, d f=114, p=0.98$, whereas among the Arab teachers, this correlation is negative and statistically significant $r=-0.33, d f=128, p<0.001$; we plotted the interaction in accordance with Aiken and West's technique (Aiken et al. 1991); see Fig. 1. 


\section{Students}

Table 5 shows the averages of the variables measured among the students, the Pearson correlations between them and their Cronbach's alpha internal reliability score. Selected demographic variables are also provided in the Table. As demonstrated, very strong positive and statistically significant correlations were found between technological abilities, attitudes towards studying online and success in studying online. We can also see in the Table that the Arab students request assistance less than others when they encounter difficulties in online learning. A weak but statistically significant positive correlation was found between attitudes towards online learning and requesting assistance. Thus, the more the student had greater positive attitudes towards online learning, the more he or she would ask for assistance from others when needed. Another weak and significant positive correlation was found between the grade and capability, where the higher the grade the greater the sense of technological ability reported by the students

The research hypotheses presumed that a connection would be found between gender and grade level and the dependent variables: success in online studies, technological abilities, attitudes towards online learning and asking for help. Again, the hypotheses were examined by means of multivariate analysis that includes several dependent variables (Three-Way MANOVA). The grade variable was reduced to three categories: (1) grades three and four, (2) grades five and six, (3) grades 7-9. Thus, the model was 2 (male/female students $\times 2$ (Jewish/Arab sector) $\times 3$ (grades three and four, grades five and six, grades seven to nine), with four dependent variables (success, ability, attitudes and asking for help). A three-way interaction was found for the variable of requesting help $F(1,465)=5.24, p=0.02$. We did not find any three-way interaction for the success variable $F(1,465)=0.02, p=0.88$, the technological ability $F(1,465)=0.07, p=0.80$ or the attitudes towards online learning variable $F(1,465)=0.01, p=0.93$. In order to interpret the three-way interaction that was found, we decided to divide the sample into female and male students. A significant two-way interaction was found for the female students between the sector and grade, $F(2,256)=8.62, p<0.001$. In order to interpret the two-way interaction, we again divided the combined grade sample into the three grade categories. We found differences between Jewish female students and Arab female students only for the highergrade level (7th to 9th grades) regarding the requesting help variable. Thus, Jewish female students in these grades $(n=67)$ ask for help more $(M=2.98$, $\mathrm{SD}=0.76)$ than Arab female students $(n=78, M=2.12, \mathrm{SD}=0.78)$, with statistical significance. In addition the findings show that among the Arab female students there are differences between the grade levels in reference to this variable $F(2,280)$ $=3.98, p=0.02$. Scheffe's post hoc test determined that Arab female students in the 7 th to 9 th grades $(n=137)$ ask for help less $(M=2.13, \mathrm{SD}=0.86)$ than Arab female students in 5th and 6th grades $(n=78, M=2.48, \mathrm{SD}=0.92)$ and Arab female students in 3rd and 4th grades $(n=68, M=2.32, \mathrm{SD}=0.94)$. We did not find a two-way interaction between the sector and the grade level among the male students. Nonetheless, we did find a simple main effect for the sector $F(1,256)=$ $10.38, p=0.001$, where the Jewish male students request assistance $(n=87, M=$ $2.67, \mathrm{SD}=0.81)$ more than the Arab male students $(n=127, M=2.22, \mathrm{SD}=0.92)$, 


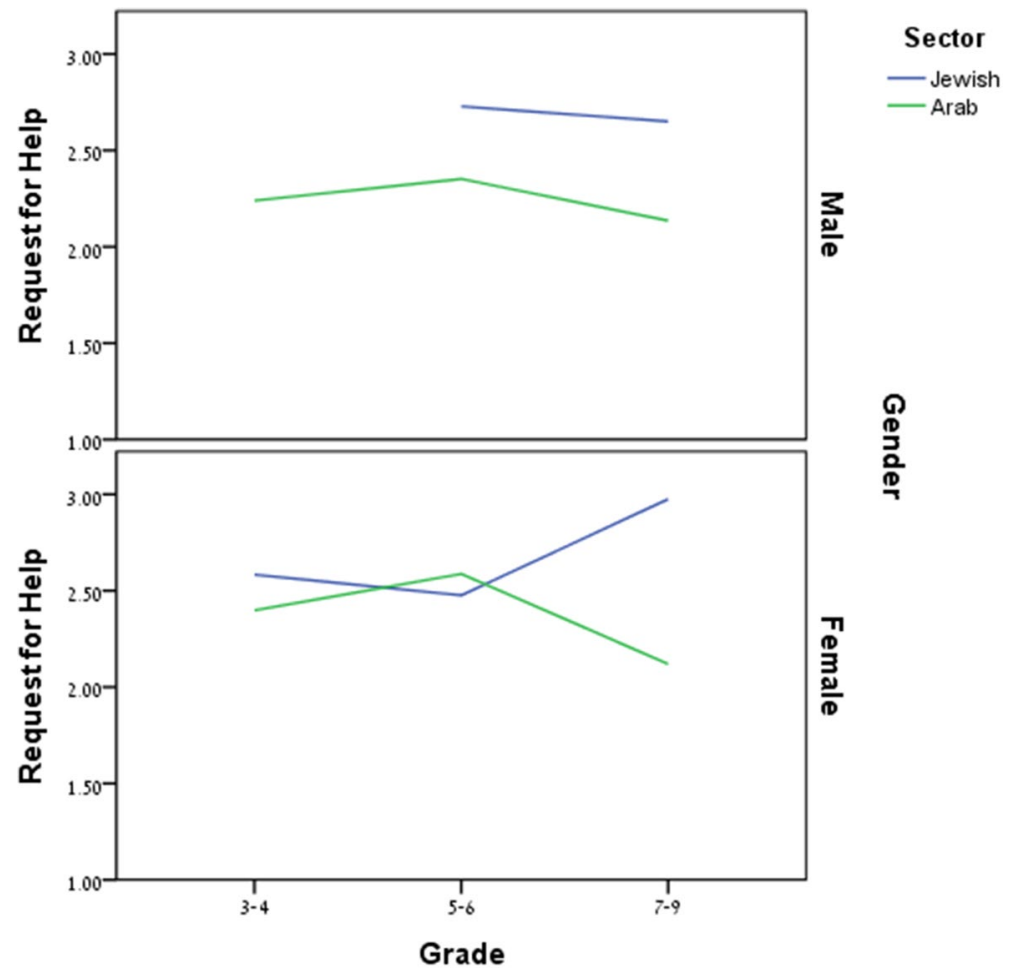

Fig. 2 Distribution of gender, sector and grade for the variable of request for help

without any connection to the grade level. In addition, the Jewish middle school students $(n=127)$ ask for help $(M=2.82, \mathrm{SD}=0.77)$ more than Arab middle school students $(n=137, M=2.13, \mathrm{SD}=0.86)$ : see Fig. 2 . Note: In 3rd and 4th grades, the number of Jewish male students was too low $(5>n)$ to calculate the average and thus they are not depicted in the figure.

A two-way interaction with marginal significance was found between gender and sector where the dependent variable was technological ability, $F(1,465)=3.40, p=$ $0.066 .{ }^{1}$ In order to break down the interaction, the sample of students was separated into female and male students. The findings show that among the female students there is no difference between the Arab and Jewish students in reference to their degree of technological abilities $t(260)=0.11, p=0.92$, where the average of the two groups was moderate, 3.30. In contrast, among the male students, the Jewish students were found to have a statistically significant higher level of technological abilities than the Arab students, $t(212)=2.68, p=0.008$ (see Fig. 3). From the

\footnotetext{
1 Because the grade is connected to the sector (where there is over-representation in the lower grades for the Jewish sector) and because the grade level was found to be connected to ability, in order to take a conservative approach, we decided to conduct an additional analysis in which the grade level was a fixed covariate. This analysis improved the model which was found to have a significance level of 0.053 .
} 


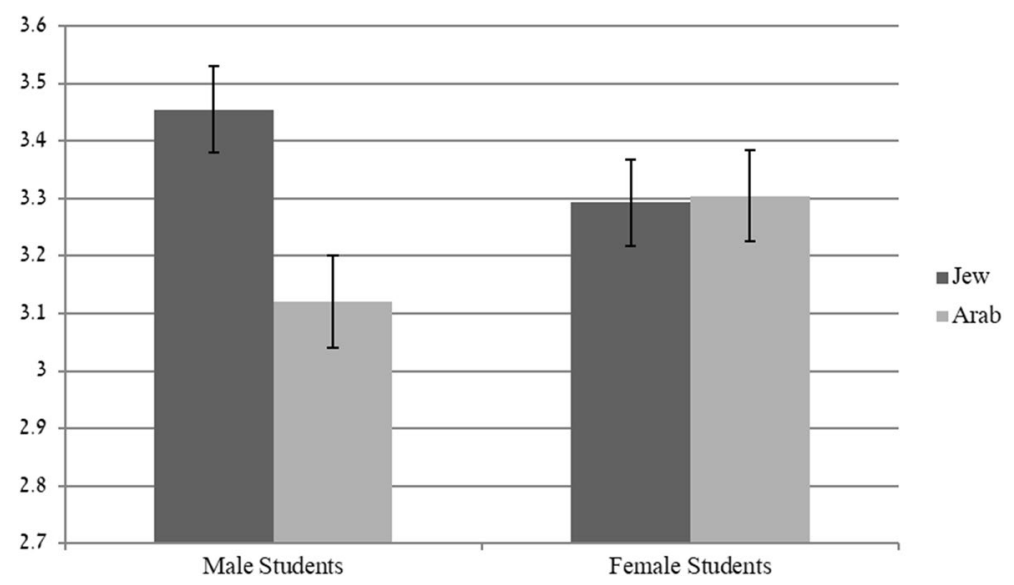

Fig. 3 Technological abilities dependent on sector and gender

perspective of the attitudes variable, a main effect was found for the sector, $F(1,476)$ $=4.70, p=0.03$, where the Jewish students had more positive attitudes towards online learning $(M=3.14, \mathrm{SD}=0.78)$ than the Arab students $(M=2.90, \mathrm{SD}=$ 0.99). No other significant main effects were found in this model.

\section{Discussion}

The aim of the study was to examine the attitudes of teachers and students, Jews and Arabs, from elementary and middle schools towards combined online teaching and learning during the outbreak of the coronavirus pandemic. Another goal was to check whether underprivileged populations (women, Arabs, older) and young students would be affected by the sudden and abrupt transition to online learning.

In accordance with the research hypotheses, older teachers were found to have lower technological abilities than the younger teachers and consequently teach online less. In addition, the age of the teacher was found to be more critical in the Arab society, where older Arab teachers were found to have relatively low technological abilities. The findings also show that male teachers have higher technological abilities than female teachers, beyond the sector and type of schools (elementary or middle school). Among the students, the higher grades and Jewish students were found to have higher technological abilities. In addition, when encountering difficulties during online learning the Arab students, especially Arab female students in the higher classes were found to ask for help less. Furthermore, the Arab students have more negative feelings towards online learning.

Earlier studies indicate that teachers have a significant role in motivating online learning (Anderson et al. 2001). The success of online teaching is greatly dependent on the technological abilities and skills of the teacher (Schleicher 2020), thus the fact that, in general, there are teachers with lower technological abilities cannot be ignored. 
The gaps between teachers from the perspective of technological abilities are critical. The findings of this study indicate that teachers with lower levels of technological abilities tend to utilize the numerous possibilities less. Conceivably, these teachers do not make use of the different features available in the different online teaching systems. These findings correspond with the studies presented in the review of literature which found a negative correlation between the age of the teacher and the attitudes and the use of information technologies, namely technological abilities (Ganayem et al. 2009; Hung and Hsu 2007). Consequently, it is not unfounded to presume that the quality of the instruction of teachers with lower technological abilities would be affected by the transition to online teaching. The problem becomes even greater when a certain sector, such as the Arab Sector in Israel (Ayalon et al. 2019) might be affected because the older (and in particular the female) teachers who teach according to this method have less technological abilities.

This study indeed reveals that the association between the age of the teachers and their technological abilities is especially apparent among the Arab teachers. Support for this finding can be found in an earlier study (Ganayem et al. 2009) which shows an advantage among younger generations over older generations in the use of technologies, as well as a digital divide that exists between the Arab society and the Jewish society (Ganayem 2018). This has affected the integration of computerization in accordance with the national program for the computerization of the education system in the Arab sector, due to the lack of computer labs and training of teachers in the field of computers in the education system in this sector (Husny-Arar and Massry-Herzallah 2016). Nonetheless, seemingly there is room for optimism in light of the findings in this study indicating that this gap does not exist among the young teachers. The finding that male teachers have higher technological capabilities than female teachers is not surprising and corresponds with earlier studies (Masry-Herzallah and Amzalag 2019). Furthermore, it is well known that the scope of the use of the Internet as well as the diverse use of its contents is greater among men (Rafaeli et al. 2018).

In the comparison between sector and type of school (elementary versus middle school) from the perspective of the scope of the use of online teaching, an interesting interaction was revealed. Namely, the findings do not reveal differences between Jewish and Arab teachers in the extent of the use of online teaching in middle schools. In contrast, Jewish teachers make more use of online teaching than Arab teachers in elementary school. The gaps found between some of the Jewish teachers and the Arab teachers can be explained by means of three factors. The first is at the level of the policy of the Ministry of Education, i.e. the main platforms of online teaching are in the Hebrew language and the majority of the contents designated for online teaching are in the Hebrew language; the second level, namely the technological ability of the teacher, is relatively lower among the Arab teachers in elementary schools, where the majority of the teachers are women. Furthermore, the digital divide between the male and female teachers as revealed in this study correspond with the finding revealed in earlier studies (Amzalag and Masry-Herzallah 2021). Teachers in the education system and especially in elementary school, receive little or no training in online teaching, synchronous or asynchronous. Nonetheless, during the coronavirus crisis they were required to undergo the transition to 
online teaching with no prior preparation (Dahan et al. 2020). The third factor we suggest originates at the student level. The lack of computers in the Arab families, the lack of infrastructure, the inability of the parents to assist their children with online learning serve as obstacles for teachers teaching online studies in elementary school and apparently to a lesser degree in higher levels of education. These findings correspond with the findings presented in earlier studies (Dynarski 2018; Reich et al. 2020).

It is possible that students in higher grades have more access to technological devices (mainly smartphones). Thus, the problem is greater among the younger students. Perhaps the lower level of access among the elementary school children in the Arab sector causes difficulties among them, which is connected to the lower use of online learning. The scarcity of online learning in elementary schools in the Arab sector, which in times of emergency is not only to teach, but also to provide emotional response to the students as well as a social-educational support framework, might affect the wellbeing of the students (Elias et al. 2019). In addition, it might widen the educational gaps between the strong students and the underprivileged students and the Jewish society and the Arab society.

This study is unique in examining online learning among elementary and middle school students. As presumed the findings in this study show a positive correlation between the student's grade and technological abilities. These results support up to date findings that have revealed that online learning can provide only partial response to this population of students, since it does not suit young students in elementary school. Elementary school students will seemingly find it difficult to succeed without full supervision and assistance on the part of their parents (Welner 2020). Moreover, preliminary findings concerning online teaching during the virus outbreak show that young students are incapable of participating in online study activities for the amount of time that is equivalent to a routine day in school (Reich et al. 2020). They are in a developmental stage that requires interpersonal interaction and communication carried out face to face both with the teacher and with peers (Kintsakis and Rangoussi 2017).

The findings concerning the students indicate a strong correlation between technological abilities and attitudes towards online learning, and between the attitudes and succeeding in studies in this manner. In other words, the study shows that when a student feels independently capable in the virtual environment and has command of the platform in which the lesson is being given, he will have more positive attitudes towards online learning, and he will enjoy a higher feeling of success. Earlier studies indeed demonstrate that the sense of technological capabilities is positively associated with the student's achievements (Aldhafeeri et al. 2006; Masry-Herzallah and Da'as 2020). As for the correlation between gender and sector and technological abilities among the students, the study findings indicate gaps between Jewish students and Arab students regarding this context. The findings show that while among the female students no differences exist between Jewish and Arab students in reference to technological abilities, among male students a significant gap exists in favour of Jewish students.

These findings correspond with Ahmed's (2009) claim that the gender differences regarding the use of information systems in the Arab society are disappearing due to 
the growing use of the technology on a daily basis among both genders. The use of information systems in the Arab education from a young age has influenced the perception of female students and their interest in studying this subject, in addition to the effect of the environment on the Arab society or the different stereotypes towards the technology. Equal exposure of the two genders is beneficial and has a more positive effect on female students than male students because it refutes the stereotypes and allows the female students the opportunity to gain experience in the subject and sense their abilities. These findings correspond with the result of the school efficiency and growth indices tests that show that in elementary and middle schools, in the Arab sector, there is clear preference of female students over male students in all subjects including math and technology, which is maintained in the technological-occupational track as well (Ayalon et al. 2019).

One of the strategies for coping with a low sense of ability and difficulties is to ask for help from others, such as parents or tutors. This study examined this strategy and found that there are significant differences regarding this issue as well. Arab students in almost every grade turn for help less and this gap is especially prominent among female students in middle school. Apparently, this population, which comprises two underprivileged populations (women and Arabs), find it more difficult to ask others for assistance.

Perhaps Jewish students ask for help more than Arab students due to the low socio-economic status of the Arab society in Israel and the inability of the parents to help their children with online learning. Specifically, the ability of the Arab parents to help their children apparently is lower due to the digital divide that exists also among the parents. For example, a much greater proportion of Jews are engaged in occupations that require computer knowledge (Central Bureau of Statistics 2020). Nonetheless, from the economic perspective, perhaps the enormous gaps in income between Jews and Arabs in favour of Jews (Central Bureau of Statistics 2020) result in less income that is available for tutoring among the Arab population. The findings in this study show that the Jewish students have more positive attitudes towards online learning than the Arab students. The Arab students' attitudes could stem from the fact that some of the Arab teachers have lower technological abilities than the Jewish teachers.

Because technology is an integral part of our lives, the education system will continue to use it in teaching and learning even after the current coronavirus crisis has passed. Thus, teachers in general, and those who belong to the underprivileged populations in particular must adapt both to the new teaching and learning culture, in terms of digital skills as wells as the optimal combination between synchronous and asynchronous teaching together with frontal teaching.

The success of online learning in the education system in Israel is dependent on the optimal combination of technology and pedagogy, and pedagogy with cultural relevancy in order to promote innovative teaching paradigms suitable to the culture. Thus, despite the other difficulties that it poses to students and teachers of different cultures, combined online instruction should continue. Nonetheless, the designers of online teaching models in the education system should take into account the cultural diversity in the education system, both for planning processes of professional development for the teachers and educators and in the support provided to the students of 
different cultures. Compulsory courses/lessons on skills in the digital space can be added to the curriculum for Arab students in primary school beginning in first grade, which would be taught by teachers qualified in the field in order to reduce the digital divide that exists between them and the Jewish students and train them in 21 st century skills.

\section{Study limitations}

Though current study is novel in several ways, it does have several limitations. First, the participants were recruited by means of a snowball convenience sample rather than a randomized subset of the population of interest. Furthermore, the data were provided through self-report questionnaires that may be confounded by bias reporting and common method variance. Nevertheless, in line with Podsakoff et al.'s (2000) recommendations, participants were explicitly assured of anonymity and were guaranteed that there were no right or wrong answers, thus reducing common method variance. This study is a correlative study that examined the system of relationships between the different variables. We do not know the direction of the relations; for instance, the direction of the relationship between technological abilities and asking for help is unclear. In addition, to better understand the phenomenon, future research should add narratives from study participants by means of a qualitative study. Furthermore, due to the fact that the study was conducted at the beginning of the coronavirus outbreak during the quarantine and the transition to online studies, the actual success rates of the students and teachers were not measured.

\section{Recommendations for future research}

As stated, future research should examine the actual success rates both of the teachers and of the students. It is important to examine whether the lower abilities of some of the study populations will be expressed in the final exams and whether the gaps in achievements will grow due to the transition to online learning. The current study guaranteed absolute anonymity and consequently we did not collect data on the schools in which the teachers teach. In a future study the researchers should attempt to cross-reference teachers' data and students' data and check whether the low abilities of teachers to teach online studies is expressed in the students' outcome variables (e.g. success in online studies). In addition, documentation of the schools and classes of the students will facilitate the examination of a multilevel model and an analysis that will take into account that students are nested in classes and in schools thereby avoiding biases and violation of statistical analysis (Raudenbush and Bryk 2002).

\section{The contribution of the research}

This study provides theoretical and practical innovation. The theoretical innovation includes (a) the development of the existing knowledge on online teaching; (b) the enhancement of the existing knowledge on cultural-adapted online teaching in 
routine times and in times of emergency; (c) concealed and apparent implications of the culture of online learning. The practical contribution of the study includes (1) calling attention to the importance of building online teaching in school as an efficient learning tool in routine and in emergency times; (2) emphasis on the need to implement online teaching in multicultural societies; (3) calling attention to the importance of planning, developing and implementing innovative curricula using online learning.

The findings of this study can assist education policy makers in the education system in multicultural societies or in education systems serving ethnic minorities around the world, to reach conclusions about the characteristics of online learning during the Covid-19 pandemic and its effect on broadening the gaps between the different cultures. Moreover, the study findings may assist policy makers in identifying the factors that promote culture-adapted online teaching, in developing professional training programs for educators that will focus on strengthening these factors and consequently lead to the schools successfully coping with changes, difficulties and crisis situations.

In conclusion, this study can serve as a source of knowledge and a source for future studies. The findings indicate the need to advance innovative thought and rethinking the path both from the pedagogic and the technological aspect in the Israeli education system, particularly in defining the role of the teacher after the coronavirus crisis, and ways to combine online teaching in schools. In the future, online learning will expand, and seemingly online learning is not a coronavirus episode that will pass.

Acknowledgement The authors wish to thank the teachers and the students who took part in the study, for their time and cooperation.

Author contributions SY conceived the idea. MA and SY designed the study. MA has collected data from the Arab teachers and students, SY has collected data from the Jewish teachers and students. MA and SY analysed the date and wrote the manuscript. Both authors approved the final version.

Funding No funding has been provided for this study.

Data availability The data are not publicly available due to their containing information that could compromise the privacy of research participants.

\section{Declarations}

Conflict of interest The authors declare that they have no conflict of interest.

\section{References}

Ahmed W (2009) The perception of female and male teachers at Al Qasemi College concerning the integration of information technology in teaching, and the influencing factors-case study. Gamaah 13:407-446 (Hebrew). https://www.qsm.ac.il/mrakez/asdarat/jamiea/13/heb=4=walid.pdf

Ahn J, McEachin A (2017) Student enrollment patterns and achievement in Ohio's online charter schools. Educ Res 46(1):44-57 
Aiken LS, West SG, Reno RR (1991) Multiple regression: testing and interpreting interactions. Sage Publications, Thousand Oaks

Aldhafeeri F, Almulla M, Alraqas B (2006) Teachers' expectations of the impact of e-learning on Kuwait's public education system. Soc Behav Person Int J 34(6):711-728. https://doi.org/10.2224/ sbp.2006.34.6.711

Amzalag M, Masry-Herzallah A (2021) Cultural dimensions and skills in the 21st century - the Israeli education system as a case Study. Pedag Cult Soc. https://doi.org/10.1080/14681366.2021.1873170

Anderson T, Rourke L, Garrison R, Archer W (2019) Assessing teaching presence in a computer conferencing context. Online Learn. https://doi.org/10.24059/olj.v5i2.1875

Aparicio M, Bacao F, Oliveira T (2016) An e-learning theoretical framework. Educ Technol Soc 19(1):292-307. https://drive.google.com/open?id=1yl9cJSbQW7A6LE7gXLXpIXW8faU6RXcj

Avidov-Ungar O, Eshet-Alkalai Y (2014) TPACK revisited: a systemic perspective on measures for predicting effective integration of innovative technologies in school systems. J Cogn Educ Psychol 13(1):19-31. https://www.achva.ac.il/sites/default/files/cognetive_education.pdf

Ayalon H, Blass N, Fengler Y, Shavit Y (2019) Educational inequality in Israel: From research to policy. Taub Center for Research of Social Policy in Israel. http://taubcenter.org.il/wp-content/files_mf/ educationinequalityinisraeleng.pdf

Bazzaz D (2020) Dispatches from parents: Northshore School District's first online-only day to prevent coronavirus spread. The Seattle Times. https://www.seattletimes.com/seattle-news/education/hownorthshore-parents-handled-the-first-day-of-online-learning/

Bishop J (2006) Partnership for 21st Century Skills—mission statement. https://www.imls.gov/assets/1/ AssetManager/BishopPre-Con2.pdf

Biernacki P, Waldorf D (1981) Snowball sampling: problems and techniques of chain referral sampling. Sociol Methods Res 10(2):141-163

Blass N (2019) The education system: an overview. In Weiss A (ed.). State of the nation report: society, economy and policy in Israel. Taub Center for Research of Social Policy in Israel. http://taubcenter .org.il/wp-content/files_mf/theeducationsystemanoverview2019eng.pdf

Bryant J, Bates AJ (2015) Creating a constructivist online instructional environment. Tech Trends 59(2):17-22

Campbell JL (2018) Instructional activities, online technologies, and social community in online graduate student courses. In: Scheg AG, Shaw M (eds) Fostering effective student communication in online graduate courses. IGI Global, Hershey, pp 102-117. https://doi.org/10.4018/978-1-52252682-7.ch006

Central Bureau of Statistics (2020) Manpower survey 2018. Central Bureau of Statistics. Hebrew. https:// www.cbs.gov.il/he/publications/DocLib/2020/lfs18_1782/h_print.pdf

Chauhan V (2017) Synchronous and asynchronous learning. Imperial J Interdiscip Res 3(2):1345-1348

Chou CC (2004) A model of learner-centered computer-mediated interaction for collaborative distance learning. Int J E-Learn 3(1):11-18. https://www.learntechlib.org/p/12780

Dabbagh N (2007) The online learner: characteristics and pedagogical implications. Contemp Issues Technol Teach Educ 7(3):217-226. https://www.learntechlib.org/p/22904

Dahan Y, Abu-Rabia-Queder S, Yona Y, Biton A, Hassan S, Levy G, Massalha M, Safrai Y, Pinson H (2020).Corona crisis and its affect on the Israeli education system. CrisisExperts Organization. https://www.crisis-experts.org.il/wp-content/uploads/2020/04/

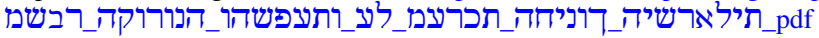

DeYoung CG, Spence I (2004) Profiling information technology users: en route to dynamic personalization. Comput Hum Behav 20(1):55-65. https://doi.org/10.1016/S0747-5632(03)00045-1

Dynarski S (2018). Online courses are harming the students who need the most help. The New York Times. https://www.nytimes.com/2018/01/19/business/online-courses-are-harming-the-studentswho-need-the-most-help.html

Elias MJ, Brackett MA, Miller RH, Jones SM, Kahn J, Mahoney JL, Weissberg RP, Chung S (2019) Developing social and emotional skills and attitudes and ecological assets. In: Osher D, Mayer MJ, Jagers RJ, Kendziora K, Wood L (eds) Keeping students safe and helping them thrive: a collaborative handbook on school safety, mental health, and wellness [2 volumes]. Praeger/ABC-CLIO, Westport, pp 185-209

Fedynich L, Bradley KS, Bradley J (2015) Graduate students' perceptions of online learning. Res Higher Educ J, 27:1-13. https://files.eric.ed.gov/fulltext/EJ1056187.pdf 
Fitzpatrick BR, Berends M, Ferrare JJ, Waddington RJ (2020) Virtual illusion: comparing student achievement and teacher and classroom characteristics in online and brick-and-mortar charter schools. Educ Res 49(3):161-175

Ford JD, Russo E (2006) Trauma-focused, present-centered, emotional self-regulation approach to integrated treatment for posttraumatic stress and addiction: trauma adaptive recovery group education and therapy (TARGET). Am J Psychother 60(4):335-355. https://doi.org/10.1176/appi.psychother apy.2006.60.4.335

Ganayem A (2018) The Internet in the Arab society in Israel: the situation, gaps and recommendations for advancement in digitization. In Proceedings of the Conference on Making Digital Pubic Services Accessible to the Arab Society

Ganayem A, Rafaeli S, Aziza F (2009) Digital divide: the use of the internet in Arab society. Megamot 46(1-2):164-196 ((Hebrew))

Hayes AF (2018) Introduction to mediation, moderation, and conditional process analysis. A regressionbased approach, 2nd edn. Guilford Press, New York

Hung Y-W, Hsu Y-S (2007) Examining teachers' CBT use in the classroom: a study in secondary schools in Taiwan. J Educ Technol Soc 10(3):233-246

Husny-Arar K, Massry-Herzallah A (2016) Motivation to teach: The case of Arab teachers in Israel. Educat Stud 42(1):19-35

Jung I, Gunawardena CN (2015) Culture and online learning: global perspectives and research. Stylus Publishing LLC, Sterling

Kale U, Goh D (2014) Teaching style, ICT experience and teachers' attitudes toward teaching with Web 20. Educ Inf Technol 19(1):41-60

Kenny DA (2020) Measuring model fit. http://www.davidakenny.net/cm/fit.htm

Kintsakis D, Rangoussi M (2017) An early introduction to STEM education: teaching computer programming principles to 5 th graders through an e-learning platform: a game-based approach. In Proceedings of the 2017 IEEE Global Engineering Education Conference (EDUCON), pp 17-23

Luthra P, Mackenzie S (2020) 4 ways covid 19 could change how we educate future generations. In Provceedings of the World Economic Forum. https://www.weforum.org/agenda/2020/03/4-ways-covid -19-education-future-generations/

Masry-Herzallah A, Amzalag M (2019) In: Eshet-Alkalai Y et al (eds) Multiculture in an online course. The Open University (Hebrew), Raanana, Israel, pp 159-163

Masry-Herzallah A, Da'as R (2020) Cultural values, school innovative climate and organizational affective commitment: a study of Israeli teachers. Int J Educat Manage. https://doi.org/10.1108/ IJEM-06-2020-0302

Moore MG, Shattuck K, Al-Harthi A (2005) Cultures meeting cultures in online distance education. J E-Learn Knowl Soc 1(2):187-207

Podsakoff PM, MacKenzie SB, Paine JB, Bachrach DG (2000) Organizational citizenship behaviors: a critical review of the theoretical and empirical literature and suggestions for future research. J Manage 26(3):513-563. https://doi.org/10.1016/S0149-2063(00)00047-7

Prensky M (2001) Digital natives, digital immigrants part 1. On Horizon 9(5):1-6. https://doi. org/10.1108/10748120110424816

R-Core-Team (2018) R: a language and environment for statistical computing. R Foundation for Statistical Computing. https://www.r-project.org

Rafaeli S, Leck E, Albo Y, Oppenheim Y, Getz D (2018) Innovative approach for measuring the digital divide in Israel: digital trace data as means for formulating policy guidelines. Samuel Neaman Institute. https://www.neaman.org.il/EN/An-Innovative-Approach-for-Measuring-the-Digital-Divid e-in-Israel-Digital-Trace-Data-as-Means-for-Formulating-Policy-Guidelines

Raudenbush SW, Bryk AS (2002) Hierarchical linear models: applications and data analysis methods, vol 1, 2nd edn. Sage, Thousand Oaks

Reich J, Buttimer CJ, Fang A, Hillaire G, Hirsch K, Larke L, Littenberg-Tobias J, Moussapour RM, Napier A, Thompson M (2020) Remote learning guidance from state education agencies during the COVID-19 pandemic: a first look. EdArXiv, April 2. https://doi.org/10.35542/osf.io/437e2

Reid-Martinez K, Grooms LD (2018) Online learning propelled by constructivism. In Encyclopedia of information science and technology, Fourth Edition. 4th ed. IGI Global, Hershey. pp 2588-2598

Reykdal C (2020) Bulletin no. 016-20 student engagement and support. Washington Office of Superintendent of Public Instruction. https://www.k12.wa.us/sites/default/files/public/bulletinsmemos/bulle tins2020/COVID-19 Guidance on Online Learning_Waivers_School Closures_as of March 62020. pdf

\section{SN Social Sciences}

A SPRINGER NATURE journal 
Rosseel Y (2012) lavaan: an R Package for structural equation modeling. J Stat Softw 48(2):1-36. https:// doi.org/10.18637/jss.v048.i02

Schleicher A (2020) How can teachers and school systems respond to the COVID-19 pandemic? Some lessons from TALIS. OECD Education and Skills Today. https://oecdedutoday.com/how-teachersschool-systems-respond-coronavirus-talis/

Seemiller C, Grace M (2017) Generation Z: educating and engaging the next generation of students. About Campus 22(3):21-26. https://doi.org/10.1002/abc.21293

Shelton BE, Hung J-L, Lowenthal PR (2017) Predicting student success by modeling student interaction in asynchronous online courses. Distance Educ 38(1):59-69. https://doi.org/10.1080/01587 919.2017.1299562

Sobodić A, Balaban I, Tomašević M (2017) The impact of cultural dimensions on student's use of E-learning system. In Proceedings of 28th Central European Conference on Information and Intelligent Systems (CECIIS 2017)

UNESCO (2020) COVID-19 educational disruption and response. Unesco.Org. https://en.unesco.org/ covid19/educationresponse

van Braak J, Tondeur J, Valcke M (2004) Explaining different types of computer use among primary school teachers. Eur J Psychol Educ 19(4):407. https://doi.org/10.1007/BF03173218

Weisblai E (2020) Distance learning during times of emergency when educational institutes are closed due to the outbreak of the Coronavirus. In Center of Research and Knowledge of the Knesset. https ://fs.knesset.gov.il/globaldocs/MMM/6c81656c-de69-ea11-8113-00155d0af32a/2_6c81656c-de69ea11-8113-00155d0af32a_11_13773.pdf

Weiss, A. (ed.) (2018) State of the nation report: Society, economy and policy in Israel. Taub Center for Research of Social Policy in Israel

Welner KG (2020) NEPC review: "public-private virtual-school partnerships and federal flexibility for schools during COVID-19." National Education Policy Cente, Boulder. http://nepc.colorado.edu/ thinktank/coronavirus 